\title{
PRODUTIVIDADE E QUALIDADE DA SOJA EM FUNÇÃO DA CALAGEM NA SUPERFÍCIE EM SEMEADURA DIRETA ${ }^{(1)}$
}

\author{
EDUARDO FÁVERO CAIRES ${ }^{(2,5)}$; ROSELI APARECIDA FERRARI ${ }^{(3)}$; \\ MARCELO ANTONIO MORGANO(4)
}

\begin{abstract}
RESUMO
As conseqüências da aplicação superficial de calcário na qualidade da soja cultivada em semeadura direta, com base nas concentrações de óleo, proteína e nutrientes, não são muito conhecidas. Com o objetivo de estudar a produtividade de grãos, óleo e proteína e a composição mineral de grãos de soja, em função da calagem na superfície, em semeadura direta, foi instalado um experimento em Latossolo Vermelho distrófico textura média, em Ponta Grossa (PR). O delineamento experimental empregado foi o de blocos ao acaso, em esquema de parcelas subdivididas, com três repetições. Em julho de 1993, foram aplicadas quatro doses de calcário dolomítico, nas parcelas, em superfície $\left(0,2,4\right.$ e 6 t.ha $\left.{ }^{-1}\right)$ e, em junho de 2000, reaplicadas duas doses de calcário dolomítico, nas subparcelas, em superfície (0 e 3 t.ha $\left.{ }^{-1}\right)$. Avaliaram-se os tratamentos por meio da cultura da soja no ano agrícola de 2001/2002. A aplicação superficial de calcário não alterou a eficiência do processo biológico de fixação de $\mathrm{N}_{2}$, avaliada pela concentração de $\mathrm{N}$ nas folhas, a produtividade de grãos, óleo e proteína de soja, apesar da elevada acidez ( $\mathrm{pH}$ em $\mathrm{CaCl}_{2} 4,3$ e $25 \%$ de saturação por bases) existente na camada superficial do solo $(0-5 \mathrm{~cm})$. A calagem na superfície, em semeadura direta, aumentou o teor de óleo e não alterou a concentração de proteína de soja. Houve aumento de $\mathrm{P}$ e Ca e redução de Zn nos grãos de soja, com a calagem na superfície, enquanto os teores de $\mathrm{K}, \mathrm{Mg}, \mathrm{Cu}, \mathrm{Mn}$ e Fe não foram alterados. As variações de $\mathrm{P}$ e $\mathrm{Zn}$ nos grãos estiveram relacionadas $(\mathrm{P}<0,01)$ com o aumento do $\mathrm{pH}$, ao passo que a de $\mathrm{Ca}$ foi proporcional $(\mathrm{P}<0,01)$ ao aumento do Ca trocável, na camada de solo de $0-5 \mathrm{~cm}$.
\end{abstract}

Palavras-chave: Glycine max (L.) Merrill, acidez do solo, calcário dolomítico, óleo, proteína, nutrientes.

\author{
ABSTRACT \\ YIELD AND QUALITY OF SOYBEAN AS AFFECTED BY SURFACE APPLICATION OF \\ LIME UNDER A NON-TILLAGE SYSTEM
}

( $\left.{ }^{1}\right)$ Trabalho realizado com auxílio financeiro do CNPq. Recebido para publicação em 10 de outubro de 2002 e aceito em 26 de maio de 2003.

$\left({ }^{2}\right)$ Departamento de Ciência do Solo e Engenharia Agrícola, Universidade Estadual de Ponta Grossa (UEPG), 84030-900 Ponta Grossa (PR). E-mail: efcaires@uepg.br

$\left({ }^{3}\right)$ Departamento de Zootecnia e Tecnologia de Alimentos, Universidade Estadual de Ponta Grossa (UEPG). E-mail: ferrarir@uepg.br

$\left({ }^{4}\right)$ Instituto de Tecnologia de Alimentos (ITAL), 13073-001 Campinas (SP). E-mail: morgano@ital.org.br

$\left({ }^{5}\right)$ Com bolsa de produtividade em pesquisa do CNPq. 
yield was evaluated in 2001/02. Liming had no effect on the efficiency of symbiotic $\mathrm{N}_{2}$ fixation, evaluated by total leaf- $\mathrm{N}$, and on soybean grain, oil and protein yields, despite the high acidity $\left(\mathrm{pH}\right.$ in $\mathrm{CaCl}_{2} 4.3$ and $25 \%$ of soil base saturation) in the soil surface layer $(0-5 \mathrm{~cm})$. Surface application of lime under a non-tillage system increased soybean oil and had no effect in protein contents. Surface liming application increased $\mathrm{P}$ and $\mathrm{Ca}$, and decreased $\mathrm{Zn}$ contents in soybean grain. The increase of $\mathrm{P}$ and the reduction of $\mathrm{Zn}$ in grains were related $(\mathrm{P}<0.01)$ to an increase of soil $\mathrm{pH}$. Also $\mathrm{Ca}$ in grains increased in the same pattern as the increase of exchangeable $\mathrm{Ca}$, in the soil surface layer $(0-5 \mathrm{~cm})$.

Key words: Glycine $\max$ (L.) Merrill, soil acidity, dolomitic limestone, oil, protein, nutrient.

\section{INTRODUÇÃO}

A soja é produzida para atender à demanda humana e animal de óleo e proteína, sendo desejável que a alta produtividade de grãos seja também acompanhada de altas concentrações desses componentes. Variações nos teores de óleo e proteína de soja resultantes do manejo da adubação ou da correção da acidez do solo têm sido relatadas na literatura (TANAKA et al., 1991, 1995; MASCARENHAS et al., 1996). Observaram-se alterações na composição mineral dos grãos de diferentes variedades de soja em função da calagem em solo ácido (SPEHAR,1994).

Na semeadura direta, a correção da acidez do solo é realizada mediante aplicação de calcário na superfície, sem incorporação. Em trabalhos recentes, têm sido verificadas respostas pouco expressivas da soja à aplicação superficial de calcário e alta produtividade da cultura em solos ácidos sob plantio direto (PöttKer e Ben, 1998; Caires et al., 1998, 1999).

A menor resposta da soja à calagem, em áreas de plantio direto, tem sido relacionada ao maior acúmulo de matéria orgânica e de nutrientes na superfície do solo que reduzem a atividade do $\mathrm{Al} \mathrm{e}$, conseqüentemente, sua toxicidade, pela formação de complexos Al-orgânicos e pela maior força iônica da solução do solo (SALET et al., 1999). Além disso, o aumento na capacidade de troca de cátions do solo, devido ao maior teor de matéria orgânica, pode proporcionar concentrações suficientes de cátions trocáveis, mesmo em solo com alta acidez (CAIRES et al., 1998). Deve-se considerar, ainda, que o plantio direto conserva a umidade nas camadas superficiais, $o$ que favorece a absorção de nutrientes pelas plantas (CAIRES e FonSECA, 2000). Todavia, faltam informações a respeito das conseqüências da acidez e das alterações químicas do solo proporcionadas pela calagem na superfície sobre a qualidade da soja.

O presente trabalho foi realizado com o objetivo de avaliar a produtividade de grãos, óleo e proteína e a composição mineral de grãos de soja cultivada em semeadura direta, considerando a aplicação de doses de calcário, sem e com sua reaplicação na superfície.

\section{MATERIAL E MÉTODOS}

O experimento foi instalado no município de Ponta Grossa (PR), Fazenda Estância dos Pinheiros, em Latossolo Vermelho distrófico, há quinze anos sob semeadura direta. Análises químicas e granulométricas do solo, da camada de $0-20 \mathrm{~cm}$, realizadas antes da instalação do experimento, revelaram os seguintes resultados: $\mathrm{pH}\left(\mathrm{CaCl}_{2}\right.$ 0,01 $\left.\mathrm{mol} \mathrm{L}^{-1}\right) 4,5 ; 58$

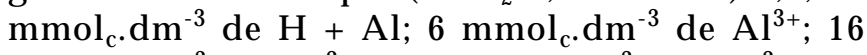
$\mathrm{mmol}_{\mathrm{c}} \cdot \mathrm{dm}^{-3}$ de $\mathrm{Ca}^{2+} ; 10 \mathrm{mmol}_{\mathrm{c}} \cdot \mathrm{dm}^{-3}$ de $\mathrm{Mg}^{2+} ; 1,4$ mmol $_{\mathrm{c}} \cdot \mathrm{dm}^{-3}$ de K $\mathrm{K}^{+} ; 9$ mg.dm ${ }^{-3}$ de P (Mehlich-1); 19 g.dm ${ }^{-3}$ de C-orgânico e 32\% de saturação por bases e teores de argila, silte e areia, respectivamente, de 220, 195 e 585 g. $\mathrm{kg}^{-1}$.

O delineamento experimental empregado foi o de blocos ao acaso em esquema de parcelas subdivididas, com três repetições. Nas parcelas de $50,4 \mathrm{~m}^{2}(6,3$ x 8,0 m), foram aplicadas, em julho de 1993, quatro doses de calcário dolomítico em superfície, com $84 \%$ de PRNT: 0, 2, 4 e 6 t.ha $^{-1}$, calculadas visando elevar a saturação por bases da camada de $0-20 \mathrm{~cm}$ de solo a $50 \%, 70 \%$ e $90 \%$. Em junho de 2000 , as parcelas foram divididas em duas subparcelas de $25,2 \mathrm{~m}^{2}(6,3 \mathrm{x}$ $4,0 \mathrm{~m}$ ): sem e com a reaplicação de $3 \mathrm{t} \mathrm{ha}^{-1}$ de calcário dolomítico em superfície, com $89 \%$ de PRNT. Essa dose foi calculada visando elevar a saturação por bases a $65 \%$, considerando a análise química de amostra de solo retirada da camada de $0-20 \mathrm{~cm}$, do tratamento que havia recebido 4 t.ha ${ }^{-1}$ de calcário $\left(\mathrm{pH}\right.$ em $\mathrm{CaCl}_{2} 0,01$ mol L ${ }^{-1}=4,6$, CTC a pH 7,0 = 110,8 mmol $_{\text {c. }} \cdot \mathrm{dm}^{-3}$ e $41 \%$ de saturação por bases). A reaplicação de calcário na superfície foi realizada com o intuito de ampliar os valores de atributos químicos do solo relacionados à acidez.

No período compreendido entre novembro de 1993 e maio de 2001, foram utilizados na rotação de culturas: soja (1993/1994), ervilhaca + aveia-preta (inverno/1994), milho (1994/1995), pousio (inverno/ 1995), soja (1995/1996), trigo (inverno/1996), soja (1996/1997), triticale (inverno/1997), soja (1997/1998), aveia-preta (inverno/1998), soja (1998/1999), aveiapreta (inverno/1999), soja (1999/2000), aveia-preta (inverno/2000), milho (2000/2001) e aveia-preta (inverno/2001). 
A semeadura da soja, cultivar COODETEC 206, foi feita em 11 de novembro de 2001, na densidade de 20 sementes por metro e espaçamento de $0,45 \mathrm{~m}$ entre as linhas. A adubação utilizada na semeadura foi de $220 \mathrm{~kg}$.ha ${ }^{-1} \mathrm{da}$ fórmula 2-20-20. As sementes foram submetidas à inoculação com Bradyrhizobium japonicum. A temperatura média do ar e a precipitação pluvial durante o ciclo da cultura foram, respectivamente, de $22^{\circ} \mathrm{C}$ e $770 \mathrm{~mm}$.

No início do florescimento da cultura, foi feita amostragem de folhas, coletando-se a terceira folha a partir do ápice das plantas, em número de 30 por subparcela, para análise química dos teores de nutrientes, de acordo com MaLAVOLta et al. (1997).

Após a maturação, a soja foi colhida e trilha$\mathrm{da}$, sendo então determinada a produtividade de grãos a 130 g. $\mathrm{kg}^{-1}$ de umidade. Colheram-se as seis linhas centrais por três metros de comprimento em cada subparcela. As amostras de grãos foram moídas para a determinação dos teores de proteína e óleo. Para estimar o teor de proteína bruta, determinou-se o teor de nitrogênio total pelo método Kjeldahl cujo valor foi multiplicado pelo fator convencional 6,25. Determinouse o teor de óleo, gravimetricamente, após extração das amostras com hexano, a quente, em extrator Soxhlet, segundo o método da Association of Official Agricultural Chemists (1955). Para a análise dos teores de nutrientes nos grãos, pesou-se, em triplicata, 1,5 g do material em cápsula de porcelana e, em seguida, as amostras foram incineradas em chapa elétrica até carbonização. Posteriormente, as amostras foram transferidas para mufla a $450{ }^{\circ} \mathrm{C}$ por oito horas. As cinzas foram dissolvidas com ácido nítrico concentrado e transferidas quantitativamente para balão volumétrico de $50 \mathrm{~mL}$. As determinações de $\mathrm{P}, \mathrm{K}, \mathrm{Ca}$, $\mathrm{Mg}, \mathrm{Cu}, \mathrm{Zn}, \mathrm{Mn}$ e Fe foram feitas mediante leitura em espectrômetro de emissão de plasma (ICP-OES).

Após a colheita, coletaram-se 12 subamostras de solo por subparcela, com trado calador, para compor uma amostra composta das camadas de 0-5, 5-10 e 10-20 $\mathrm{cm}$ de profundidade. Foram determinados o $\mathrm{pH}$ e os teores de $\mathrm{H}+\mathrm{Al}, \mathrm{Al}^{3+}, \mathrm{Ca}^{2+}, \mathrm{Mg}^{2+}, \mathrm{K}^{+}$e P (Mehlich-1), segundo PAVAN et al. (1992), e os resultados, submetidos às análises de variância e de regressão polinomial.

Foram ajustadas equações de regressão aos dados obtidos, a partir das doses de calcário, adotando-se como critério para escolha do modelo a magnitude dos coeficientes de determinação, significativos a $5 \%$. Na ausência de interação significativa entre as doses e a reaplicação de calcário, as equações foram ajustadas pelas médias das observações. Os efeitos da reaplicação de calcário foram comparados pelo teste F.

\section{RESULTADOS E DISCUSSÃO}

A aplicação de doses de calcário na superfície aumentou o $\mathrm{pH}$, os teores de $\mathrm{Ca}$ e $\mathrm{Mg}$ trocáveis e a saturação por bases e reduziu os teores de $\mathrm{H}+\mathrm{Al}$ e de Al trocável, nas três profundidades estudadas, com efeitos mais acentuados na camada próxima à superfície do solo (Quadro 1).

Os efeitos da reaplicação de calcário na superfície sobre tais variáveis também ocorreram em maior magnitude na camada superficial do solo e, principalmente, em condições de acidez elevada. Assim, as plantas de soja cresceram em variadas condições de acidez do solo, conforme idealizado no estudo. Os teores de $\mathrm{K}$ trocável e de $\mathrm{P}$ disponível não foram influenciados pela calagem.

Os tratamentos de calcário não proporcionaram alterações significativas na produtividade de grãos e nos teores de N nas folhas de soja (Quadro 2). Houve eficiência do processo biológico de fixação de $\mathrm{N}_{2}$ e alta produtividade de grãos, apesar da elevada acidez existente na camada superficial do solo ( $\mathrm{pH}$ em $\mathrm{CaCl}_{2} 4,3$ e $25 \%$ de saturação por bases).

A importância da correção da acidez para a melhoria da eficiência da fixação simbiótica de $\mathrm{N}_{2}$ e produtividade de soja cultivada em preparo convencional do solo foi demonstrada por MASCARENHAS et al. (1996).

Em solos ácidos sob plantio direto, no Sul do Brasil, absorção adequada de $\mathrm{N}$ pela soja e alta produtividade da cultura têm sido observadas mesmo sem correção da acidez (PÖTTKER e BEN, 1998; CAIRES et al., 1998, 1999; CAIRES e FONSECA, 2000). Esse comportamento da soja cultivada em plantio direto pode estar associado à menor concentração de espécies tóxicas $\left(\mathrm{Al}^{3+}\right.$ e $\left.\mathrm{AlOH}^{2+}\right)$ e maior concentração de $\mathrm{Al}$ complexado com ligantes orgânicos (MiYAZAWA et al., 1996; SALET et al., 1999), aliado à maior disponibilidade de Ca e Mg trocáveis no solo (CAIREs et al., 1998). Cabe ressaltar que maiores respostas da soja à calagem, independentemente do sistema de manejo, têm sido observadas em solos com menores teores de Mg trocável (Mascarenhas et al., 1996; Oliveira e PAVAN, 1996).

O teor de óleo de soja aumentou de forma quadrática com as doses de calcário, sendo a máxima concentração obtida com 3,2 t.ha ${ }^{-1}$ de calcário (Figura 1). A reaplicação de calcário na superfície elevou o teor de óleo de 187 para 191 g.kg-1 ${ }^{-1}$, diferença não significativa. Os trabalhos de TANAKA et al. (1991) e MASCARENHAS et al. (1996) demonstraram que o teor de óleo de soja foi reduzido com a calagem e aumentado com a adubação potássica (TANAKA et al., 1995). 
Quadro 1. Resultados de análises químicas de amostras de solo, coletadas em três profundidades após a colheita da soja, em função de quatro doses de calcário sem e com a sua reaplicação na superfície em semeadura direta

\begin{tabular}{|c|c|c|c|c|c|c|c|c|c|}
\hline \multirow{2}{*}{ Profundidade } & \multirow{2}{*}{ Calcário } & \multirow{2}{*}{$\begin{array}{l}\mathrm{pH} \text { em } \\
\mathrm{CaCl} 2\end{array}$} & \multirow{2}{*}{$\mathrm{H}+\mathrm{Al}$} & \multicolumn{4}{|c|}{ Cátions trocáveis } & \multirow{2}{*}{$\begin{array}{c}\mathrm{P} \\
(\text { Mehlich-1) }\end{array}$} & \multirow{2}{*}{$\begin{array}{r}\text { Saturação } \\
\text { por bases }\end{array}$} \\
\hline & & & & $\mathrm{Al}^{3+}$ & $\mathrm{Ca}^{2+}$ & $\mathrm{Mg}^{2+}$ & $\mathrm{K}^{+}$ & & \\
\hline $\mathrm{cm}$ & t.ha ${ }^{-1}$ & & & \multicolumn{4}{|c|}{$\mathrm{mmol}_{\mathrm{c}} \cdot \mathrm{dm}^{-3}$} & $\mathrm{mg} \cdot \mathrm{dm} \mathrm{m}^{-3}$ & $\%$ \\
\hline \multicolumn{10}{|c|}{ Sem reaplicação de calcário } \\
\hline \multirow[t]{4}{*}{$0-5$} & 0 & 4,3 & 99 & 8 & 19 & 11 & 2,5 & 8,9 & 25 \\
\hline & 2 & 4,5 & 84 & 3 & 25 & 13 & 1,5 & 7,3 & 32 \\
\hline & 4 & 5,1 & 65 & 0 & 45 & 17 & 2,5 & 9,9 & 50 \\
\hline & 6 & 5,1 & 61 & 0 & 42 & 18 & 2,1 & 10,0 & 50 \\
\hline \multirow[t]{4}{*}{$5-10$} & 0 & 4,2 & 103 & 9 & 12 & 10 & 1,6 & 5,7 & 19 \\
\hline & 2 & 4,5 & 82 & 4 & 21 & 14 & 1,3 & 3,9 & 31 \\
\hline & 4 & 4,8 & 76 & 2 & 32 & 13 & 1,6 & 5,1 & 38 \\
\hline & 6 & 4,8 & 72 & 2 & 28 & 17 & 1,2 & 3,9 & 39 \\
\hline \multirow[t]{4}{*}{$10-20$} & 0 & 4,2 & 103 & 9 & 10 & 10 & 1,5 & 2,5 & 17 \\
\hline & 2 & 4,5 & 84 & 4 & 15 & 12 & 1,6 & 1,4 & 25 \\
\hline & 4 & 4,6 & 81 & 3 & 22 & 13 & 1,4 & 1,9 & 31 \\
\hline & 6 & 4,5 & 82 & 4 & 18 & 18 & 1,2 & 2,0 & 31 \\
\hline \multicolumn{10}{|c|}{ Com reaplicação de 3 t.ha $a^{-1}$ de calcário } \\
\hline \multirow[t]{4}{*}{$0-5$} & 0 & 5,0 & 63 & 0 & 36 & 20 & 2,4 & 10,8 & 48 \\
\hline & 2 & 5,4 & 51 & 0 & 49 & 31 & 2,4 & 8,5 & 62 \\
\hline & 4 & 5,4 & 54 & 0 & 51 & 29 & 2,1 & 7,5 & 60 \\
\hline & 6 & 5,5 & 49 & 0 & 46 & 30 & 1,8 & 13,3 & 61 \\
\hline \multirow[t]{4}{*}{$5-10$} & 0 & 4,3 & 94 & 7 & 15 & 13 & 1,6 & 3,4 & 24 \\
\hline & 2 & 4,7 & 80 & 3 & 27 & 16 & 1,5 & 2,4 & 36 \\
\hline & 4 & 4,9 & 67 & 1 & 32 & 15 & 1,3 & 2,8 & 42 \\
\hline & 6 & 4,8 & 68 & 1 & 30 & 13 & 1,1 & 5,4 & 39 \\
\hline \multirow[t]{4}{*}{$10-20$} & 0 & 4,3 & 90 & 6 & 14 & 11 & 1,4 & 2,9 & 23 \\
\hline & 2 & 4,6 & 84 & 4 & 17 & 15 & 1,4 & 1,4 & 28 \\
\hline & 4 & 4,7 & 78 & 2 & 25 & 12 & 1,1 & 1,8 & 33 \\
\hline & 6 & 4,6 & 78 & 3 & 18 & 18 & 1,4 & 2,2 & 32 \\
\hline
\end{tabular}

Quadro 2. Produtividade de grãos e concentração de nitrogênio nas folhas de soja em função de quatro doses e da reaplicação de calcário na superfície em semeadura direta

\begin{tabular}{lcc}
\hline Tratamento & Produtividade de grãos & Nitrogênio nas folhas \\
\hline & $\mathrm{kg} \cdot \mathrm{ha}^{-1}$ & $\mathrm{~g} \cdot \mathrm{kg}^{-1}$ \\
Calcário, t.ha ${ }^{-1}$ & & 53,5 \\
0 & 3.648 & 50,3 \\
2 & 3.602 & 53,2 \\
4 & 3.633 & 53,2 \\
6 & 3.644 & $\mathrm{~ns}$ \\
Efeito & $\mathrm{ns}$ & 6,6 \\
C.V. (\%) & 7,0 & \\
Reaplicação de calcário & & 51,8 \\
Sem calcário & 3.640 & 53,3 \\
Com 3 t.ha ${ }^{-1}$ & 3.624 & $1,53 \mathrm{~ns}$ \\
Valor F & $0,03 \mathrm{~ns}$ & 5,6 \\
C.V. (\%) & 6,5 & \\
\hline
\end{tabular}

ns = não significativo. 

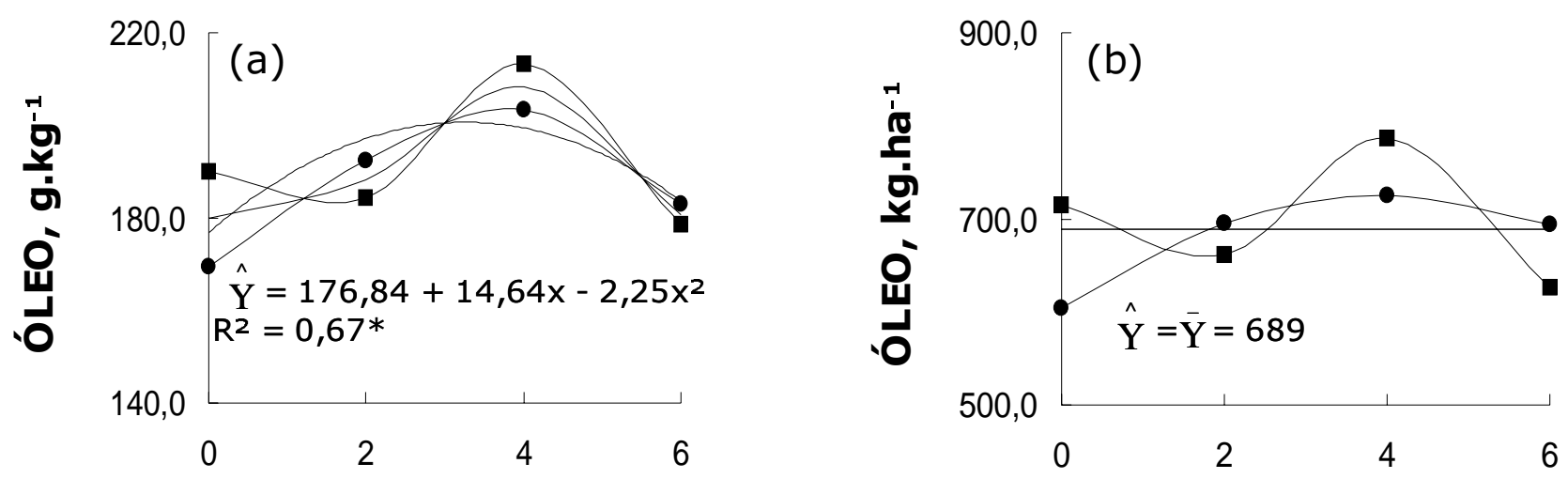

\section{CALCÁRIO, t.ha-1}

Figura 1. Concentração (a) e produtividade (b) de óleo de soja em função de quatro doses de calcário na superfície, sem $(\bullet)$ e com $(\square)$ a reaplicação de calcário, em semeadura direta. ${ }^{*}=$ significativo $\mathrm{P}<0,05$.

As relações entre os cátions $(\mathrm{Ca}+\mathrm{Mg}) / \mathrm{K}$ do solo variaram de 12 a 42 e as relações $\mathrm{K} / \mathrm{Ca}$ e $\mathrm{K} / \mathrm{Mg}$ no tecido foliar de 3,7 a 2,6 e de 6,3 a 4,6, respectivamente, com os tratamentos de calagem. É possível que a pequena substituição de $\mathrm{K}$ por $\mathrm{Ca}$ e $\mathrm{Mg}$ no tecido foliar, ocorrida com a calagem, tenha contribuído para aumentar a concentração de óleo. Também é importante observar que os menores teores de óleo foram obtidos em condições extremas de acidez ou de correção da acidez do solo.

Mesmo assim, a produtividade de óleo de soja não foi influenciada significativamente pelas doses de calcário, tendo-se obtido $689 \mathrm{~kg} \cdot \mathrm{ha}^{-1}$. Os tratamentos de calcário não causaram alterações significativas na concentração e produtividade de proteína de soja (Figura 2). $\mathrm{O}$ teor foi de $346 \mathrm{~g} \cdot \mathrm{kg}^{-1}$ e a produtividade, de $1.256 \mathrm{~kg} . \mathrm{ha}^{-1}$ de proteína. Há uma relação inversa en- tre o teor de óleo e o de proteína em soja (BRIM, 1973). No presente trabalho, as relações proteína/óleo variaram de 1,7 a 2,0, ficando muito próximas das obtidas por TANAKA et al. (1995) e MASCARENHAS et al. (1996).

A calagem, geralmente, aumenta a concentração e a produtividade de proteína em soja (TANAKA et al., 1991, 1995; MASCARENHAS et al., 1996), pela melhoria nas condições de fixação biológica do $\mathrm{N}_{2}$, em vista da redução da acidez do solo e pelo aumento na disponibilidade de Mo (QuAGGIO et al., 1998).

No entanto, para a soja cultivada em semeadura direta, a correção da acidez do solo, por meio da aplicação superficial de calcário (Quadro 1), não alterou a eficiência do processo biológico de fixação de $\mathrm{N}_{2}$ avaliada pela concentração de $\mathrm{N}$ nas folhas (Quadro 2) e, conseqüentemente, o teor e a produtividade de proteína de soja (Figura 2).
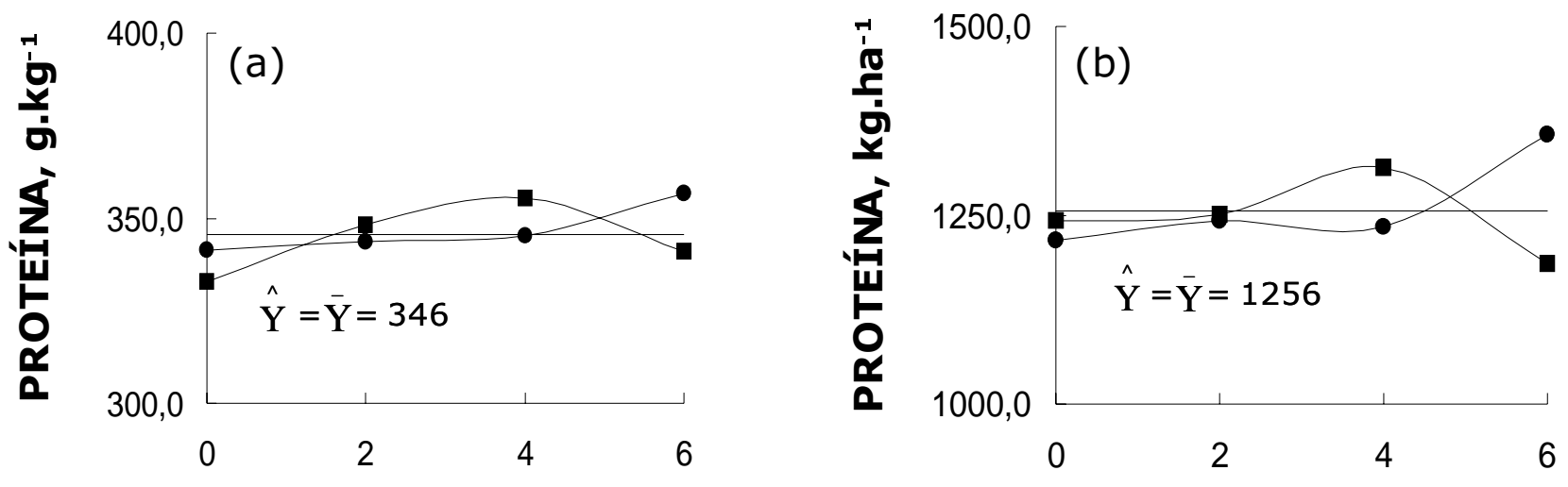

CALCÁRIO, t.ha-1

Figura 2. Concentração (a) e produtividade (b) de proteína de soja em função de quatro doses de calcário na superfície, sem $(\bullet)$ e com (ロ) a reaplicação de calcário, em semeadura direta. 

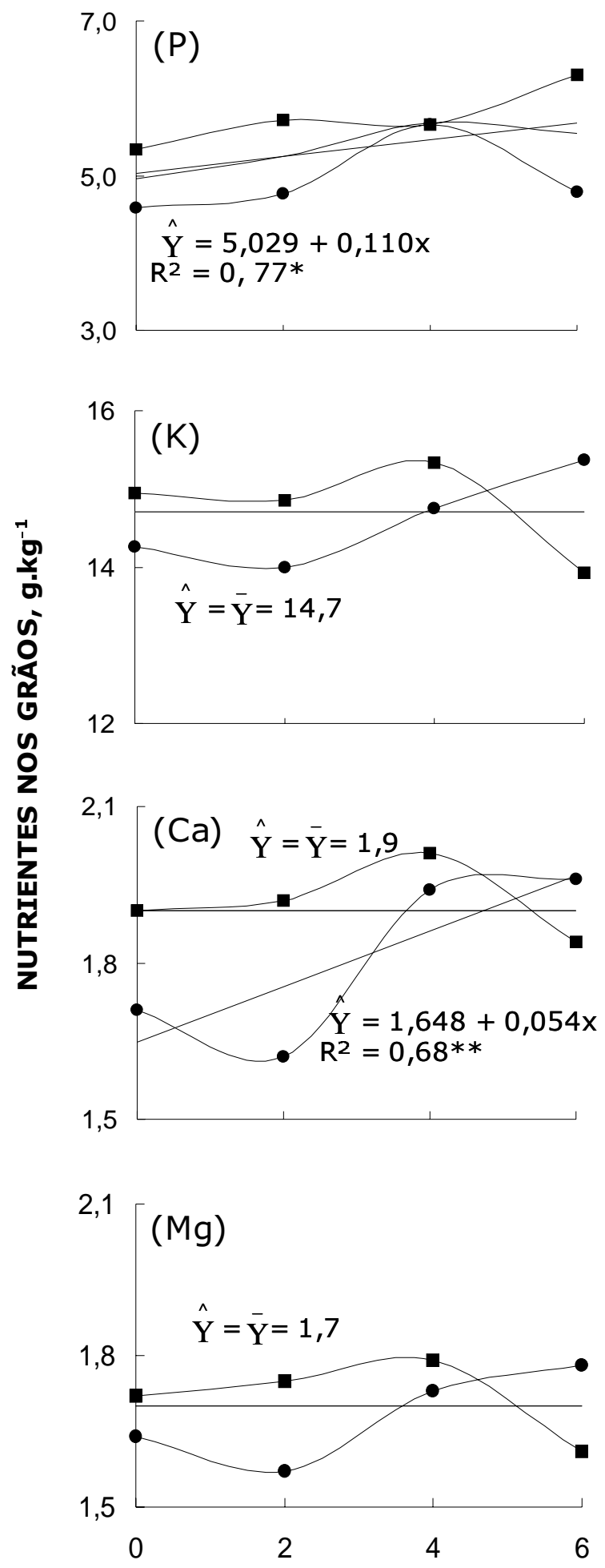

(Cu)

11

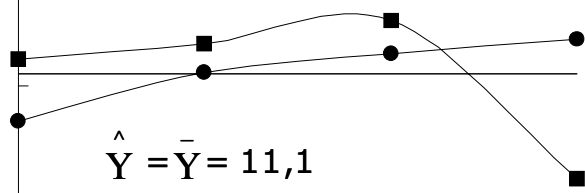

9

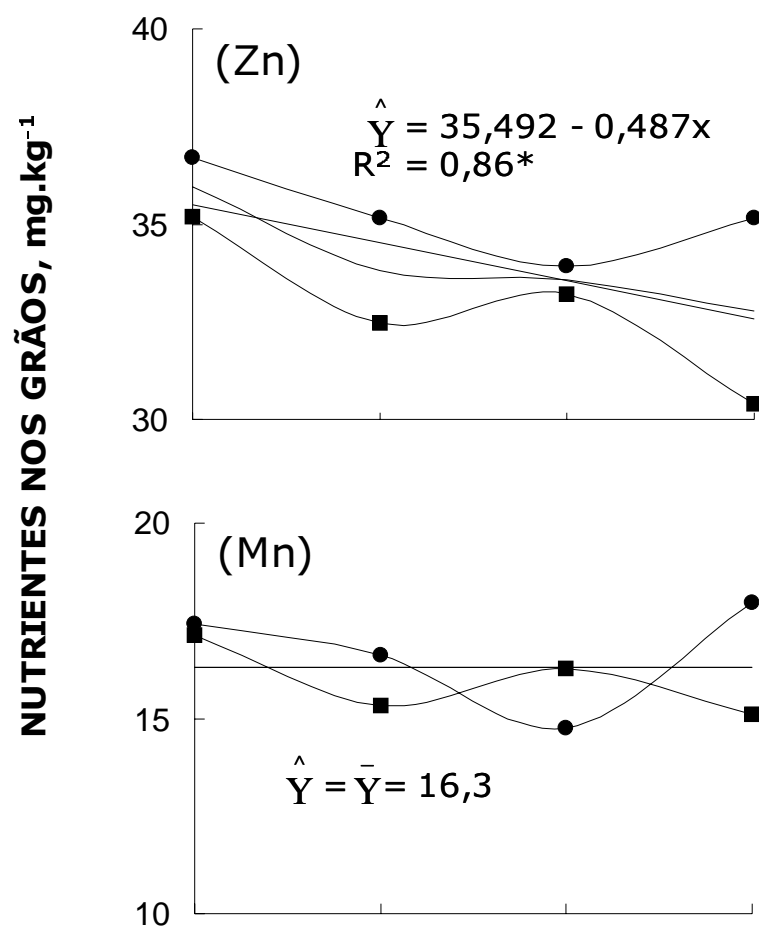

120

(Fe)

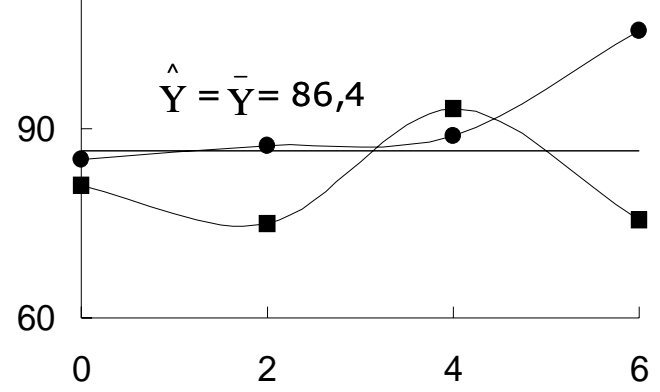

CALCÁRIO, t.ha-1

Figura 3. Concentração de nutrientes nos grãos de soja em função de quatro doses de calcário na superfície, sem ( $\bullet$ ) e com $(\square)$ a reaplicação de calcário, em semeadura direta. ${ }^{*}=$ significativo $\mathrm{P}<0,05 \mathrm{e}^{* *}=$ significativo $\mathrm{P}<0,01$. 
Os teores de P, Ca e Zn nos grãos de soja foram influenciados pelos tratamentos, tendo ocorrido interação significativa entre doses e reaplicação de calcário somente para o teor de Ca (Figura 3). As doses de calcário aumentaram $\mathrm{P}$ e reduziram $\mathrm{Zn}$ nos grãos, de forma linear. Considerando a média das doses de calcário, a reaplicação do corretivo no solo elevou o $\mathrm{P}$, de 4,9 para $5,8 \mathrm{~g} \cdot \mathrm{kg}^{-1}$, e diminuiu o $\mathrm{Zn}$, de 35,2 para $32,8 \mathrm{mg} \cdot \mathrm{kg}^{-1}$, nos grãos de soja. A concentração de Ca nos grãos foi aumentada linearmente com a aplicação superficial de doses de calcário, somente na ausência de reaplicação do corretivo.

A reaplicação de calcário na superfície aumentou o teor de Ca nos grãos, apenas nas doses $0 \mathrm{e}$ 2 t.ha $^{-1}$ de calcário. As concentrações de $\mathrm{K}, \mathrm{Mg}, \mathrm{Cu}$, Mn e Fe nos grãos não foram alteradas com a calagem. SPeHAR (1994), em trabalho realizado com doses de calcário ( 1 e 4 t.ha ${ }^{-1}$ ) e 45 variedades de soja cultivada em solo de cerrado, observou que o aumento da dose do corretivo não causou alterações nos teores de $\mathrm{Ca}$ e $\mathrm{Mg}$ e resultou em concentrações mais baixas de $\mathrm{P}, \mathrm{K}, \mathrm{Cu}, \mathrm{Zn}, \mathrm{Mn}$ e Fe nas sementes.

$\mathrm{O}$ autor considera que a variabilidade genética para acumulação de elementos minerais está presente em germoplasmas de soja.

Os resultados mostraram que o aumento de $\mathrm{Ca}$ (CAires et al., 2001) e P (CAIRes e Fonseca, 2000; CAires et al., 2001) e a redução de Zn (Mascarenhas et al., 1988; CAIRES e FonseCA, 2000), absorvidos pelas plantas de soja com a calagem, têm reflexos nos teores desses nutrientes nos grãos. Ressalta-se a importância do aumento de Ca e P nas sementes de soja para a melhoria de sua qualidade fisiológica.

$\mathrm{O}$ aumento do teor de $\mathrm{P}$ nos grãos, considerando os tratamentos de calcário (Figura 3), esteve relacionado de forma significativa $(\mathrm{P}<0,01)$ com o aumento do $\mathrm{pH}$ do solo na profundidade de $0-5 \mathrm{~cm}$ $(\mathrm{r}=0,86)$, apesar da disponibilidade de $\mathrm{P}$ no solo não ter sido alterada com a calagem (Quadro 1).

A concentração de Ca nos grãos de soja relacionou-se positiva e significativamente $(\mathrm{P}<0,01) \mathrm{com}$ o Ca trocável no solo na profundidade de $0-5 \mathrm{~cm}(\mathrm{r}=$ 0,86 ), oriundo da maior reação do calcário principalmente em condições de acidez mais elevada (Quadro 1).

A redução do teor de $\mathrm{Zn}$ nos grãos, com a calagem (Figura 3), relacionou-se de forma significativa $(\mathrm{P}<0,01)$ com o aumento do $\mathrm{pH}$ do solo na profundidade de $0-5 \mathrm{~cm}(\mathrm{r}=-0,85)$. Esse fato se explica pela menor disponibilidade de $\mathrm{Zn}$ a valores elevados de $\mathrm{pH}$ (LiNDSAY, 1972). Outros fatores também podem estar envolvidos, como a interação entre Zn e P (Paulsen e Rottimi, 1968), em razão de aumento da absorção de P com a calagem.
A importância do aumento do $\mathrm{pH}$, Ca trocável e saturação por bases, na profundidade de $0-5 \mathrm{~cm}$, para a produção acumulada de grãos de culturas em rotação no plantio direto, foi demonstrada por CAIRES et al. (2000). No presente trabalho, as alterações nos teores de P, Ca e Zn nos grãos de soja também ocorreram em vista da reação do solo na camada superficial $(0-5 \mathrm{~cm})$, com a aplicação de calcário em superfície.

\section{CONCLUSÕES}

1. A concentração de $\mathrm{N}$ nas folhas e a produtividade de grãos, óleo e proteína de soja não são influenciadas pela aplicação superficial de calcário em solo ácido, com teores suficientes de $\mathrm{Ca}, \mathrm{Mg}$ e $\mathrm{K}$ trocáveis, em semeadura direta.

2. A calagem na superfície, em semeadura direta, aumenta o teor de óleo e não causa alterações na concentração de proteína de soja.

3. A aplicação superficial de calcário aumenta os teores de $\mathrm{P}$ e $\mathrm{Ca}$, reduz a concentração de $\mathrm{Zn}$ e não altera os teores de $\mathrm{K}, \mathrm{Mg}, \mathrm{Cu}, \mathrm{Mn}$ e Fe nos grãos de soja. O aumento de $\mathrm{P}$ e Ca e a redução de $\mathrm{Zn}$ nos grãos de soja ocorrem em vista da reação do calcário na camada de solo de $0-5 \mathrm{~cm}$.

\section{REFERÊNCIAS BIBLIOGRÁFICAS}

ASSOCIATION OF OFFICIAL AGRICULTURAL CHEMISTS. Official methods of analysis. 8.ed. Washington, 1955. p.30.

BRIM, C.A. Quantitative genetics and breeding. In: CALDWELL, B.E.; HOWELL, R.W.; JUDD, R.W.; JOHNSON, H.W. (Eds.). Soybeans: improvement, production, and uses. Madison: American Society of Agronomy, 1973. p.155-186.

CAIRES, E.F.; FONSECA, A.F. Absorção de nutrientes pela soja cultivada no sistema de plantio direto em função da calagem na superfície. Bragantia, Campinas, v.59, n.2, p.213220, 2000.

CAIRES, E.F.; BANZATTO, D.A.; FONSECA, A.F. Calagem na superfície em sistema plantio direto. Revista Brasileira de Ciência do Solo, Viçosa, v.24, n.1, p.161-169, 2000.

CAIRES, E.F.; CHUEIRI, W.A.; MADRUGA, E.F.; FIGUEIREDO, A. Alterações de características químicas do solo e resposta da soja ao calcário e gesso aplicados na superfície em sistema de cultivo sem preparo do solo. Revista Brasileira de Ciência do Solo, Viçosa, v.22, n.1, p.27-34, 1998.

CAIRES, E.F.; FONSECA, A.F.; FELDHAUS, I.C.; BLUM, J. Crescimento radicular e nutrição da soja cultivada no sistema plantio direto em resposta ao calcário e gesso na superfície. Revista Brasileira de Ciência do Solo, Viçosa, v.25, n.4, 1029-1040, 2001. 
CAIRES, E.F.; FONSECA, A.F.; MENDES, J.; CHUEIRI, W.A.; MADRUGA, E.F. Produção de milho, trigo e soja em função das alterações das características químicas do solo pela aplicação decalcário e gesso na superfície, em sistema de plantio direto. Revista Brasileira de Ciência do Solo, Viçosa, v.23, n.2, p.315-327, 1999.

LINDSAY, W.L. Inorganic phase equilibria of micronutrients in soils. In: MORTVEDT, J.J.; GIORDANO, P.M.; LINDSAY, W.L. (Eds.). Micronutrients in agriculture. Madison: Soil Science Society of America, 1972. p.41-57.

MALAVOLTA, E.; VITTI, G.C.; OLIVEIRA, S.A. Avaliação do estado nutricional das plantas: princípios e aplicações. 2.ed. Piracicaba: Associação Brasileira para Pesquisa da Potassa e do Fosfato, 1997. 319p.

MASCARENHAS, H.A.A.; BATAGLIA, O.C.; QUAGGIO, J.A.; GALLO, P.B. Zinco nas folhas de soja em função da calagem. Bragantia, Campinas, v.47, n.1, p.137-142, 1988.

MASCARENHAS, H.A.A.; TANAKA, R.T.; GALLO, P.B.; PEREIRA, J.C.V.N.A.; AMBROSANO, G.M.B.; CARMELLO, Q.A.C. Efeito da calagem sobre a produtividade de grãos, óleo e proteína em cultivares precoces de soja. Scientia Agrícola, Piracicaba, v.53, n.1, p.164-172, 1996.

MIYAZAWA, M.; PAVAN, M.A.; SANTOS, J.C.F. Effects of addition of crop residues on the leaching of $\mathrm{Ca}$ and $\mathrm{Mg}$ in Oxysols. In: INTERNATIONAL SYMPOSIUMON PLANT-SOIL INTERACTIONS AT LOW pH, 4., Belo Horizonte, 1996. Abstracts... Belo Horizonte: Sociedade Brasileira de Ciência do Solo/EMBRAPA-CPAC, 1996. p.8.

OLIVEIRA, E.L.; PAVAN, M.A. Control of soil acidity in notillage system for soybean production. Soil ETillage Research, Amsterdam, v.38, p.47-57, 1996.
PAULSEN, S.M.; ROTTIMI, O.A. Phosphorus-zinc interaction in two soybean varieties differing in sensibility to phosphorus nutrition. Soil Science Society of America Journal, Madison, v.32, p.73-76, 1968.

PAVAN, M.A.; BLOCH, M.F.; ZEMPULSKI, H.C.; MIYAZAWA, M.; ZOCOLER , D.C. Manual de análise química do solo e controle de qualidade. Londrina: Instituto Agronômico do Paraná, 1992. 38p. (Circular, 76).

PÖTTKER, D.; BEN, J.R. Calagem para uma rotação de culturas no sistema plantio direto. Revista Brasileira de Ciência do Solo, Viçosa, v.22, n.4, p.675-684, 1998.

QUAGGIO, J.A.; GALLO, P.B.; FURLANI, A.M.C.; MASCARENHAS, H.A.A. Isoquantas de produtividade de soja e sorgo para níveis de calagem e molibdênio. Revista Brasileira de Ciência do Solo, Viçosa, v.22, n.2, p.337-344, 1998.

SALET, R.L.; ANGHINONI, I.; KOCHHANN, R.A. Atividade de alumínio na solução de um solo no sistema plantio direto. Revista Científica Unicruz, Cruz Alta, v.1, p.9-13, 1999.

SPEHAR, C.R. Seed quality of soya bean based on mineral composition of seeds of 45 varieties grown in a Brazilian Savanna acid soil. Euphytica, Dordrecht, v.76, p.127-132, 1994.

TANAKA, R.T.; MASCARENHAS, H.A.A.; MIRANDA, M.A.C. Effect of liming on soybean protein and oil yield. Better Crops International, Atlanta, v.7, n.2, p.9, 1991.

TANAKA, R.T.; MASCARENHAS, H.A.A.; REGITANOD'ARCE, M.A.B.; GALLO, P.B. Concentração e produtividade de óleo e proteína de soja em função da adubação potássica e da calagem. Pesquisa Agropecuária Brasileira, Brasília, v.30, n.4, p.463-469, 1995. 